\title{
ARQUITETURA VERNACULAR NO SERTÃO DE ITAPARICA-PE: EXPERIÊNCIA DE REGISTRO COMO MEMÓRIA
}

\author{
Raisa Carvalho* \\ Mércia Carréra ${ }^{* *}$ \\ Leandro Surya ${ }^{* * *}$
}

RESUMO: $O$ artigo tem o intuito de apresentar parte dos resultados do inventário das edificações vernaculares do Sertão de Itaparica - PE. Para tal, debateu-se o conceito de Arquitetura Vernacular. Foram estudados 28 exemplares durante os trabalhos de campo. Os dados coletados foram registrados em plantas baixas (croquis), fotografias e formulários de dados. Identificou-se técnicas construtivas, materiais utilizados nas construções e tipos de acabamento. Como resultado três padrões de plantas foram identificados, sendo estas plantas quadradas ou retangulares, plantas longitudinais e plantas em $\mathrm{L}$.

Palavras-chave: Arquitetura de Terra, Técnicas construtivas, Memória.

ABSTRACT: The article intends to present part of the results of the vernacular buildings inventory of the Sertão de Itaparica - PE. For this, the concept of Vernacular Architecture was debated. Twenty-eight buildings were studied during the field work. The collected data were recorded on lower floors (sketches), photographs and data forms. It was identified constructive techniques, materials used in constructions and types of finishing. As a result, three plant patterns were identified, being these square or rectangular plants, longitudinal plants and $L$ plants.

Keywords: Earth Architecture, Constructive Techniques, Memory.

\footnotetext{
* Arquiteta, pesquisadora da ZDB Produções.

** Faculdade Damas - FADIC

*** Universidade Federal do Vale do São Francisco UNIVASF
} 


\section{Introdução}

Este artigo é resultado de uma pesquisa sobre a arquitetura vernacular no sertão de Itaparica em Pernambuco. Uma pesquisa interdisciplinar utilizando os conhecimentos tanto da Arquitetura como da Arqueologia no processo da realização do registro documental deste patrimônio edificado do sertão pernambucano.

A arquitetura estudada por meio da arqueologia aborda as edificações enquanto materialização de formas de pensar o espaço para atender necessidades individuais e coletivas que refletem, intrinsecamente, hábitos, costumes e interesses dos grupos sociais em um determinado tempo e espaço (Carréra e Surya, 2012).

A Arqueologia da Arquitetura é definida como a disciplina através da qual se elabora a história de um edifício, analisando a construção de um ponto de vista arqueológico, sob a premissa de que o próprio edifício fará parte da cultura material da comunidade que nele interviu. 0 edifício, ou conjunto edificado, passará então a ser observado de uma forma mais crítica e mais abrangente, analisando-se não só estilística e arquitetonicamente, mas também estratigraficamente, de forma a registar e analisar todos os momentos da sua existência (Mañana Borrazás, et alii, 2002; Mannoni e Boato, 2002).

O sertão de Itaparica é uma microrregião do estado de Pernambuco, representado por uma cultura, influenciada por um entrelaçamento de povos de matrizes indígenas, europeia e africana, que é caracterizada em suas construções e traçados históricos. Dentro do recorte espacial foram pesquisados os municípios de Floresta e Carnaubeira da Penha.

A Fundação Nacional de Saúde (Funasa) realizou naquela área um programa de melhorias habitacionais para o controle da doença de Chagas, tendo como agente patogênico o Trypanosoma cruzi, popularmente conhecido no Brasil como Barbeiro ou Bicudo. Esses municípios encontram-se classificados com alto risco de transmissão, tendo como principal abrigo desses transmissores as residências vernaculares, como as casas de taipa, pau-a-pique, madeira, ficando instalados nas frestas dessas estruturas.

O projeto da Funasa tem como intuito reformar ou demolir essas construções, dependendo da gravidade e das condições existentes. Com isso descaracterizando parte do acervo vernacular da região estudada, sendo mais um motivo para se registrarem essas edificações (Funasa, 2014).

\section{Arquitetura Vernacular}

A palavra vernáculo tem origem do latim Vernaculum, que significa escravo nascido na casa do senhor. Vernáculo representa aquilo que é próprio de uma região, de uma nação na qual está inserido (Ferreira, 2001). Estudar a arquitetura vernacular é entender todos os aspectos culturais, sociais e geográficos aos quais ela está submetida. Para Costa (2002, p. 33) "é a arquitetura regional autêntica, tem as suas raízes na terra. É produto espontâneo das necessidades e conveniências da economia e do meio físico e social". 
A arquitetura vernacular distingue-se da erudita, onde a erudita é aquela feita por pessoas que passaram por escolas de arquitetura ou engenharia e a vernacular vem do saber popular, do cotidiano. A distinção entre arquitetura erudita e não erudita, ou vernacular, não reside nas características do edifício em si, mas no modo pelo qual foram concebidos e executados. Em outras palavras, o sentido de erudição ou não erudição diz respeito ao tipo de conhecimento empregada no processo de produção da arquitetura considerada. (...) seria arquitetura produzida por arquitetos profissionais. (...) É importante enfatizar que a condição de ser ou não erudita não implica automaticamente em uma evidência de qualidade arquitetônica ou precariedade construtiva (Silva, 1994, p. 136).

Segundo Souza (1985, apud Teixeira, 2008: 35) "A arquitetura vernácula representa uma expressão coletiva que vêm da vivência do povo e que se desenvolve sem propostas teóricas, sem vanguardas intelectuais." São construções criadas, do conhecimento passado de geração para geração, aprendido em comunidade, gerado a partir das necessidades e recursos disponíveis.

Uma obra com características constantes, que possui autenticidade na sua expressão, e, ao mesmo tempo complexa e conservadora, uma construção adaptada ao entorno, autossuficiente, baixo conteúdo energético, autêntica, estrutura pequena, pode ser um sistema disseminado, resultado de uma produção coletiva e integração de trabalho (Lima, 2010, p. 4).

São as necessidades e o meio inserido que dizem como e quais materiais devem ser empregados, qual a melhor maneira de usá-los, qual o porte e a intenção daquela construção. Uma forma de construir partilhada pela comunidade, representando um caráter regional, que usa da sabedoria tradicional herdada informalmente, adequando-se as restrições sociais e ambientais. Tendo forte valor patrimonial, por representar a identidade cultura de cada comunidade em particular e, desta forma, afirmar esta diversidade (Icomos, 1999).

Dentre todos os conceitos que levam a identificar características únicas e especiais a esse estilo arquitetônico, é uma arquitetura sem arquitetos, onde a vida é a escola e o meio ambiente é a matéria-prima. Fugindo dos conceitos eruditos, que para ser arquitetura, tem que ser realizada por estudiosos da área.

\section{Arquitetura Vernacular no Brasil e no Sertão Nordestino}

As construções vernaculares pioneiras no Brasil surgiram com povos indígenas, que utilizavam suas próprias técnicas e materiais que a terra oferecia. A partir da colonização brasileira, começa a surgir uma fusão de conhecimentos, com influências africanas e europeias. Técnicas muito antigas, derivadas do entrelaçamento de culturas de diferentes matrizes passaram a ser adaptadas para o novo contexto colonial. Em um sistema no qual o próprio corpo foi responsável por definir os padrões de medição. As principais matérias-primas construtivas vernaculares utilizadas até os tempos atuais contam com a presença de madeiras, palhas, rochas e barro (Mendes; Verissimo e Bittar, 2011). 
Cada região do país caracteriza-se pelos seus materiais e técnicas que mais se destacam. Diferentes matérias-primas ricas em um local podem ser raras ou mesmo indisponíveis em outro. Todavia, as escolhas culturais é que determinam as formas, não a disponibilidade de materiais. Migrações que ocorrem ao longo dos séculos transformam os conhecimentos, aperfeiçoam e modificam técnicas, influenciados por clima, vegetação, modas resultando em edificação. Maneira na qual o morador que decide, julga, projeta, constrói, reforma e amplia na melhor forma para suprir a sua necessidade.

O litoral nordestino possuía um solo muito favorável ao cultivo da cana-de-açúcar, já conhecido e implantado na Europa. O restante das terras que não serviam aos colonizadores eram o que hoje se denomina sertão. Com o plantio em larga escala, começam a surgir engenhos para processar o açúcar, gerando a necessidade do gado para movimentar as moendas que não eram movidas a roda d’água (Maia, 2014).

Com o crescimento acelerado dos rebanhos, começam a surgir conflitos entre os senhores de engenho e os criadores de gado, sendo instituída em 1701, uma Carta-Régia que proibia a criação de gado em terras litorâneas, gerando a migração dos criadores e de seus rebanhos para as regiões sertanejas, seguindo o percurso dos rios secos, se alojando em cabanas. As cabanas utilizavam o couro do gado para portas e janelas, como também para confecção de objetos como arreios e vestes, como o gibão para proteção da vegetação espinhosa de com galhos secos (Maia, 2014).

Antes da chegada dos colonizadores a terras sertanejas eram os índios que a habitavam. A nação indígena Tapuia, nome genérico para os povos que viviam no interior, possuía em seus territórios grupos como os Cariri nas chapadas, Pipipã no Riacho do Navio, Rodela, nas ilhas do São Francisco, Caracu nas imediações de Serra Negra, entre outras. Após a colonização nas margens dos rios começaram a surgir as fazendas de gado, dando início aos primeiros povoados e vilas (Carvalho, 2013).

A dinâmica cultural resultante do processo colonial alterou a originalidade das técnicas de execução das edificações, daí surgindo uma hibridação destes saberes. A partir do processo de colonização de terras sertanejas, nota-se a contribuição das três etnias fundamentais, sendo as técnicas mais utilizadas nas construções sertanejas o adobe, a pau-a-pique e taipa de pilão.

\section{Arquitetura Vernacular como Patrimônio Cultural}

O patrimônio é uma representação da identidade cultural, seja ele material ou imaterial, guarda os aspectos históricos e sociais da região ao qual está inserido, exprimindo o saber de um povo.

É importante a preservação do patrimônio vernáculo, por retratar a interação da sociedade com a terra, promovendo a percepção da diversidade cultural. Onde essas construções, com o passar do tempo, vão sendo descaracterizadas e não possuem integração com a sociedade moderna (Icomos, 1999). 
Segundo Teixeira (2008, p. 42), "Por se tratar de um patrimônio cultural, sua manutenção deve ser incentivada junto as comunidades que a dentem, além de haver a conscientização, através da educação patrimonial, daqueles que passam a viver ou conviver junto a elas". Com a preservação dos bens vernaculares, não está apenas preservando uma construção, mas também todos os aspectos, costumes e técnicas que estão por trás da sua criação.

Para preservação desse patrimônio cultural, é proposta uma série de diretrizes, com objeto de apoio para conservação vernacular:

1. A conservação do património vernáculo deve ser executada por competências multidisciplinares, embora reconhecendo a inevitabilidade da mudança e do desenvolvimento, bem como a necessidade de ser respeitada a identidade cultural estabelecida.

2. O trabalho atual em edifícios, grupos e povoados vernáculos deve respeitar os respectivos valores culturais e o seu carácter tradicional.

3. Frequentemente, o vernáculo é representado apenas por estruturas únicas, e é melhor conservado pela manutenção e pela preservação de grupos de edificações e de povoados com um carácter representativo, região por região.

4. O património vernáculo edificado é uma parte integral da paisagem cultural, e este relacionamento deve ser tomado em consideração no desenvolvimento das abordagens de conservação.

5. O vernáculo abrange não só a forma e a fábrica física dos edifícios, das estruturas e dos espaços, mas também as formas pelas quais eles são usados e compreendidos, e as tradições e associações intangíveis que thes estão associadas (ICOMOS, 1999, p.3)

Seguindo os pontos de preservação apresentados, a conservação acontece de forma correta e adequada fluindo da melhor maneira. Resguardando não só a edificação, como também a paisagem e os costumes locais.

Por meio dos pontos apresentados, nota-se como a arquitetura vernácula está presente no país, porém ainda sem o reconhecimento devido. Com isso a necessidade de resguardar essas construções, que representam a população e suas origens. Tendo que haver a conscientização e o reconhecimento dos cidadãos, para poder entender que este tipo de arquitetura também é um patrimônio, sendo algo de extrema importância, que necessita de cuidados e preservação, como qualquer outra construção que tenha seu valor histórico.

\section{O Inventário}

Para elaboração de um inventário da arquitetura vernacular no Sertão de Itaparica, foi estabelecido como recorte espacial uma rota da pesquisa de campo, percorrendo o município de Floresta, com os distritos de Nazaré do Pico e Airi, e a reserva biológica da Serra Negra. Já 
no município de Carnaubeira da Penha, com os distritos de Barra do Silva, Sede, Massapê e Olho D'água do Padre, e as Serras do Arapuá e da Umã.

Durante o percurso da rota estabelecida foram observadas construções que demonstraram critérios vernaculares, ao todo se estudou 28 edificações. No protocolo para a confecção do inventário, foi efetuado o registro das edificações, com croquis de plantas baixas, fotografias e os donos ou responsáveis pelas mesmas responderam a questionários socioeconômicos, informando sobre a forma construtiva das edificações.

Em Floresta e seus distritos foi possível observar métodos construtivos diversos, tais como, casas em pau-a-pique e plantas baixas quadrangulares, outras com tijolos maciços feitos em fôrmas de madeira e assentados em barro, cujo método construtivo que se assemelha as edificações dos colonos europeus. Já outras casas possuíam tijolos de adobe, assentados em barro e rebocados em areia. As telhas, portas e janelas têm formatos maiores, são muito pesadas e possuem peitoris largos.

A edificação (figura 1) pode ser descrita em sua estrutura pela composição de toras de madeiras nativas, fincadas no solo com um emaranhado de varas perpendiculares amarradas com cipós, preenchendo as brechas com barro, na fachada frontal e parte da lateral esquerda o barro do alisado e coberto com cal. A edificação aparece com 2 alturas diferentes, vão diminuindo da fachada frontal em direção a posterior, cada bloco possui duas águas voltadas para as fachadas laterais, na estrutura da coberta foi utilizado Pereiro (Aspidosperma pyrifolium) e Algaroba (Prosopis juliflora). Para ventilação e iluminação a edificação possui duas portas feitas com Cedro (Cedrela spp.), locadas na fachada frontal e posterior e duas janelas confeccionadas com Umburana de Cheiro (Amburana cearensis).

Pelos traços visualizados a edificação apresenta três momentos construtivos diferenciados: o que hoje constitui a sala, no passado deveria ser um espaço comum; no segundo momento ocorreu a construção dos quartos e de uma cozinha aberta, e no último a cozinha foi fechada e criado o corredor ligando os espaços interiores.

Nas edificações levantadas em Carnaubeira da Penha e seus distritos encontrou-se a predominância de construções em Pau-a-Pique. Também foram constatadas edificações de tijolos maciços e fundação em pedra.

A edificação (Figura 2) pode ser descrita a partir de sua função como igreja do Sagrado Coração de Jesus, localizada no centro do distrito de Carnaubeira da Penha. Tem sua estrutura formada em tijolos de adobe, assentados em barro, revestida em areia e cal. É possível encontrar buracos nas paredes externas que mostram a junção entre os tijolos. Sua coberta é constituída em duas águas, direcionadas para as fachadas laterais, foi utilizado madeira nativa, tendo estrutura e telhas confeccionadas no local. A ventilação e iluminação são feitas por duas portas de Cedro e seis janelas confeccionadas com madeira da região. 

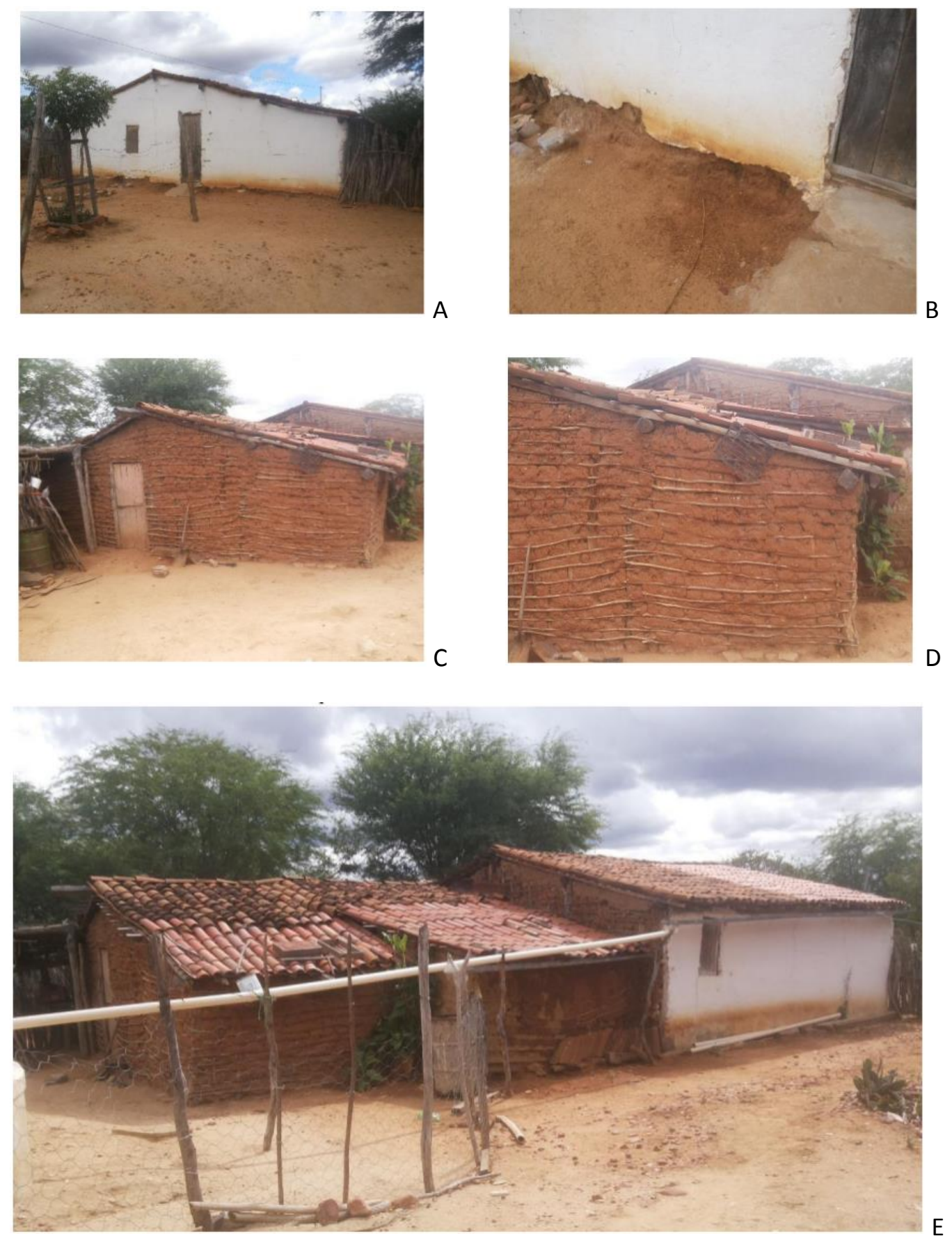

Figura 1: Exemplo de edificação de Floresta - PE: a - fachada frontal; $b$ - detalhe da base da edificação em terra feita diretamente sobre o solo, sem a presença de rochas ou outro tipo de isolamento; c fachada posterior; $d$ - detalhe construtivo da armação do madeiramento para suporte da argila; e vista lateral da edificação, pela fachada direita, no qual se destacam os três módulos construtivos. 

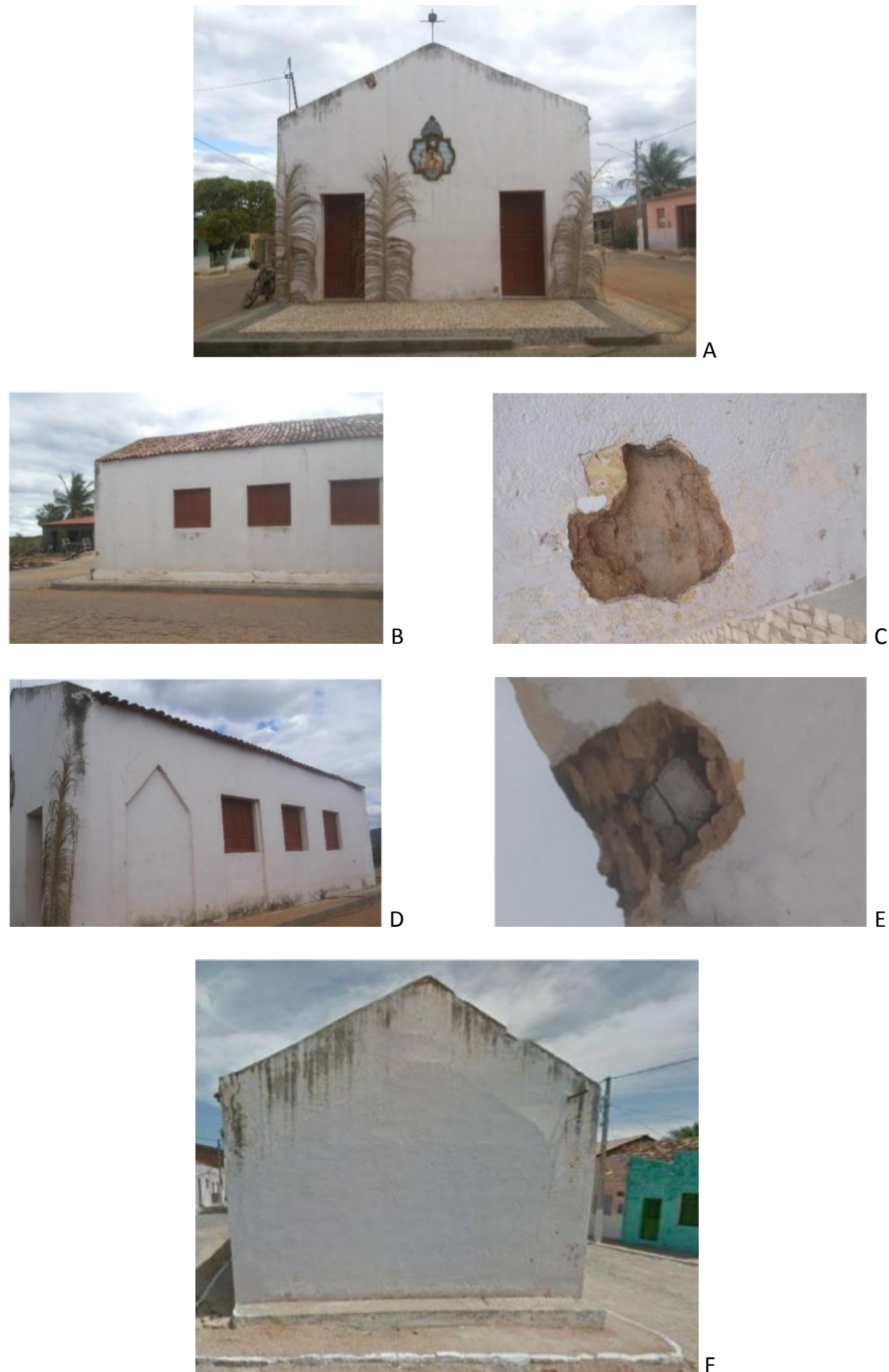

Figura 2: Exemplo da edificação de Carnaubeira da Penha, PE: a - fachada frontal; $b$ - fachada lateral direita; $c$ - detalhe construtivo; $d$ - fachada lateral esquerda; $e$ - detalhe construtivo da coberta; $f$ fachada posterior. 


\section{Considerações sobre as Edificações Inventariadas}

A análise contou com 28 edificações inventariadas, apresentando planta baixa caracterizada em três grandes grupos: as plantas quadradas ou retangulares (Figura 3); as plantas longitudinais (Figura 4) e as plantas com o perfil em L (Figura 5).

As edificações construídas com plantas quadradas ou retangulares possuem um corte temporal de 1880 até 2013, cujas dimensões variam de plantas muito complexas (21) até as mais simples de apenas um cômodo (03 e 17). Geograficamente elas se espalham em todos os locais pesquisados, o que leva a induzir uma antiguidade para o uso desta forma próxima ao início de colonização da região em estudo.

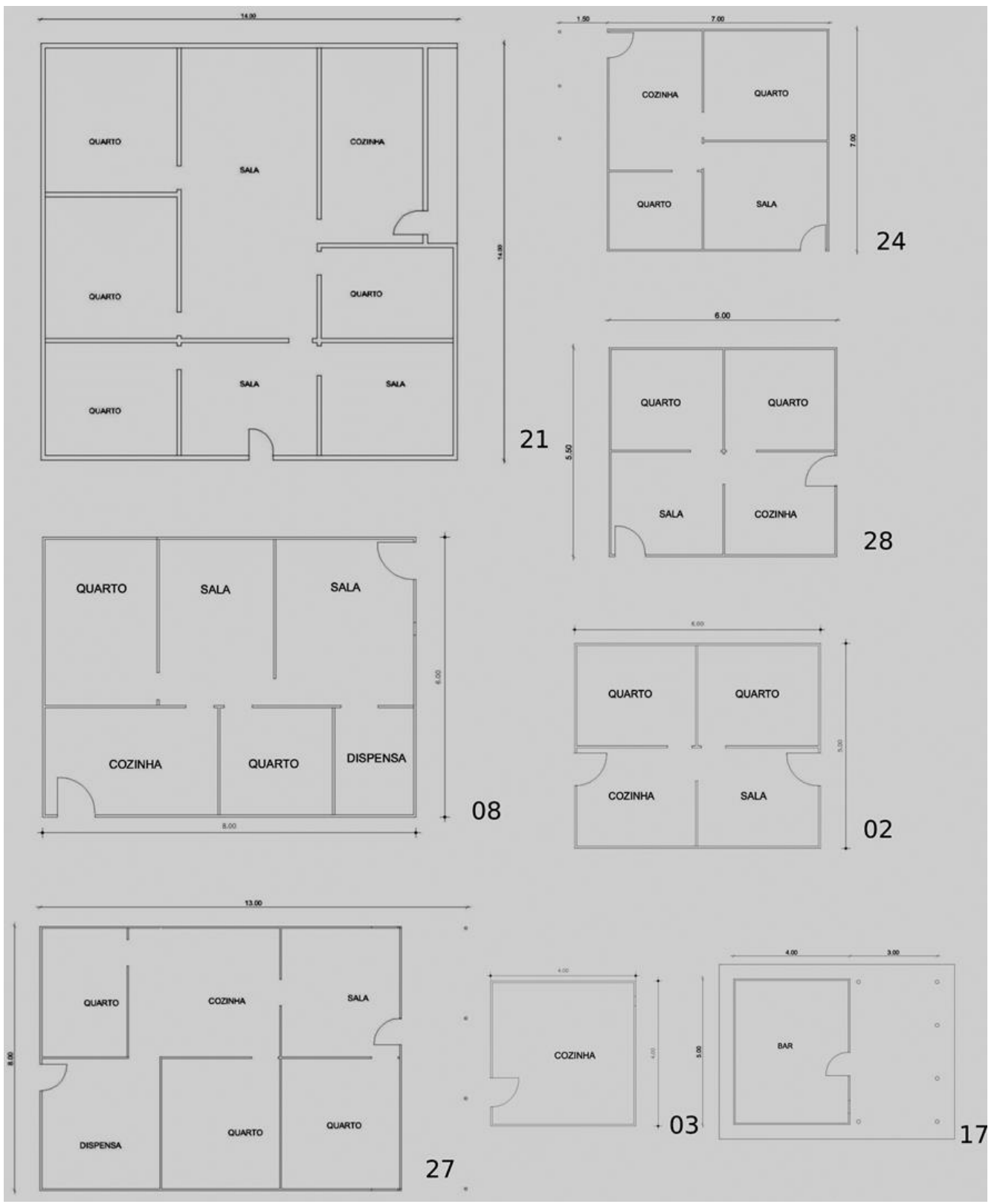

Figura 3: Conjunto das plantas levantadas com perfil quadrado ou retangular. 0 número a direita de cada planta equivale a identificação no Quadro 1. 
As edificações construídas com plantas longitudinais possuem um espaço de tempo de 1950 chegando até 2013, suas dimensões variam de plantas muito complexas (12) até as mais simples de dois cômodos (04). Geograficamente elas se espalham em todos os locais pesquisados, sua característica marcante rememora um formato de vagão, no qual, o caminhar pela casa liga diretamente a sala à cozinha, intercomunicando-se com os outros espaços.

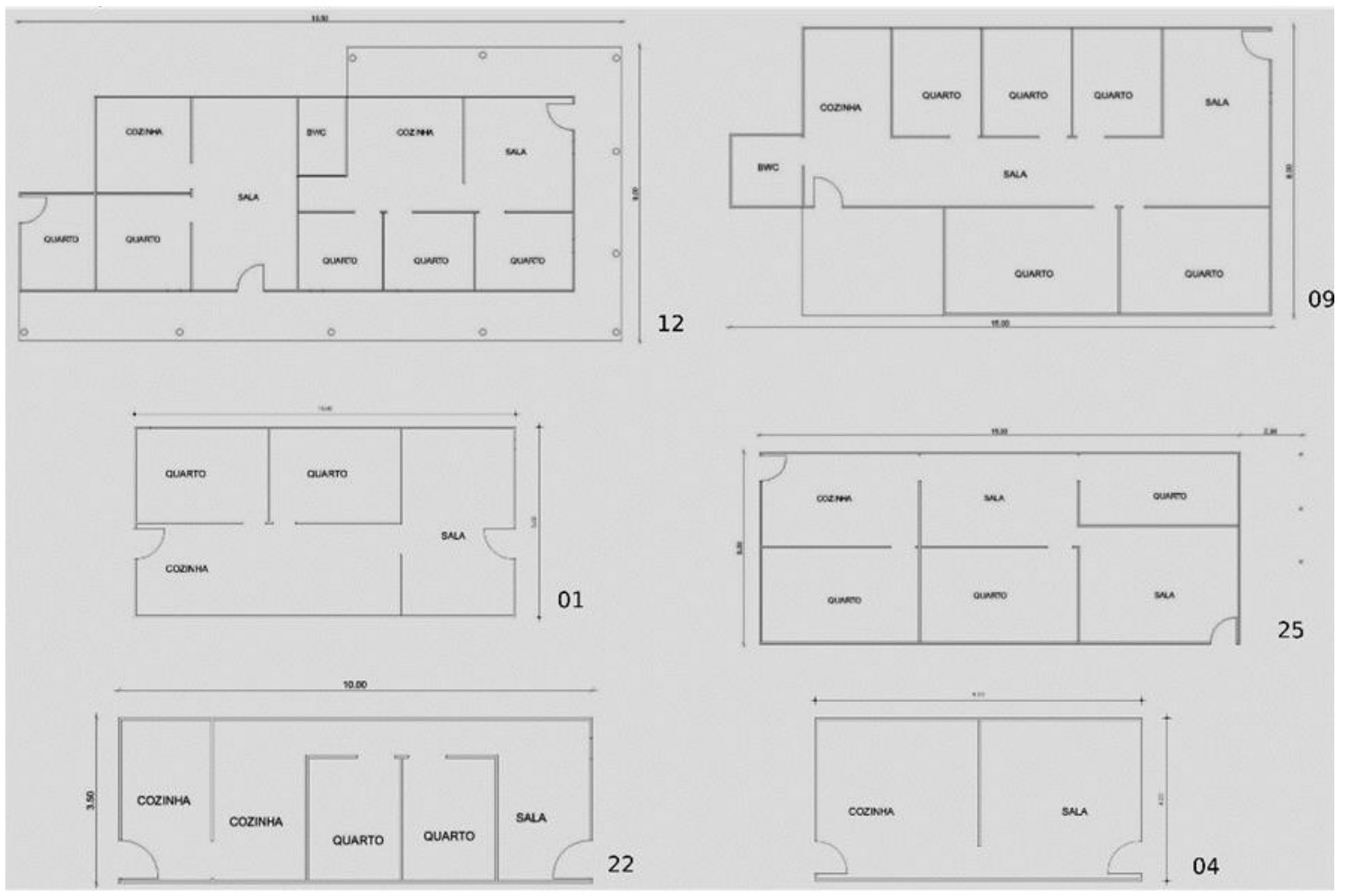

Figura 4: Conjunto das plantas levantadas com perfil longitudinal. O número a direita de cada planta equivale a identificação no Quadro 1.

As edificações construídas com plantas em L vão desde 1903 até 1999, sua principal característica é a relação de prolongamento causada por um ou mais cômodos formando um ângulo de 90 o sendo, geralmente, a cozinha. As dimensões variam de plantas muito complexas (19) até espaços mais simplificados (18). Geograficamente elas se espalham em todos os locais pesquisados

No item métodos construtivos obteve-se catorze edificações em pau-a-pique, sete de adobe, três de tijolos maciços, zero de taipa de pilão e quatro com mais de um método. Os materiais mais utilizados nas portas foram Cedro, Imburana de Cambão e Pau D'arco. Para a confecção das janelas as madeiras mais utilizadas foram a Umburana de Cheiro, Imburana Cambão (Commiphora leptophloeos) e Pau D'arco (Tabebuia serratifolia). Já para as estruturas de cobertas, as madeiras mais utilizadas foram Pereiro, Algaroba, Angico (Anadenanthera colubrina), Aroeira (Schinus terebinthifolius), Baraúna (Schinopsis brasiliensis), Carnaúba (Copernicia prunifera), Marmeleiro (Croton sonderianus), Pinho (Pinus elliottii) e, em menor 
escala, o Eucalipto (Eucalyptus spp) e a Caraíba (Cordia piauhiensis). Para as paredes os materiais mais utilizados foram o barro, areia, cal, madeiras nativas e cipós.

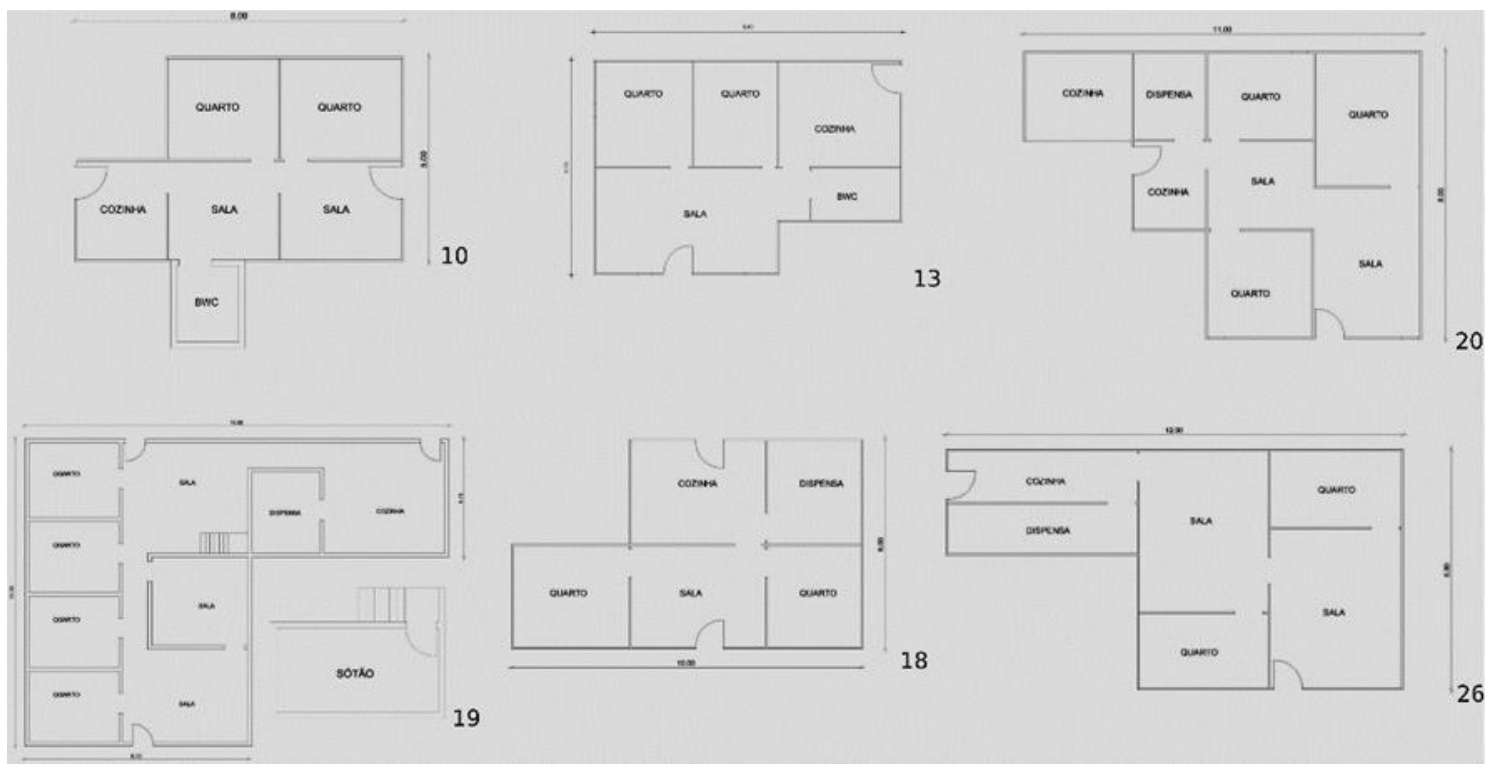

Figura 5: Conjunto das plantas levantadas com perfil em L. O número a direita de cada planta equivale a identificação no Quadro 1.

Foi observado que o formato da planta e o método construtivo influenciam um maior número de edificações. As madeiras utilizadas em diferentes construções tendem a se repetir com frequência e sempre direcionadas para o mesmo uso, seja para portas, janelas ou estruturas da coberta.

Nos três tipos de plantas foi observado que as edificações mais complexas em termos de quantidade de espaços são as mais antigas, todavia, não se pode tomar como uma regra. Isto talvez remeta a questões econômicas, cujas famílias mais abastadas hoje constroem, principalmente, com técnicas de alvenaria e apenas a parcela mais pobre da população ainda opte por uma arquitetura de terra.

O inventário permitiu perceber não só os métodos e materiais construtivos que se empregam na arquitetura vernacular no sertão pernambucano, como também todo o aspecto social e cultural em que os moradores vivem, bem como as edificações reflete diretamente no modo de vida e costumes daqueles que a utilizam. Além da importância de conscientizar a população quanto ao reconhecimento dessas edificações como patrimônio histórico e cultural local.

Diversos protocolos são possíveis de serem criados envolvendo as técnicas de coleta de materiais construtivos. Para as madeiras podem-se catalogar os tipos de cortes, furos, raspagens e ferramentas utilizadas no preparo das edificações. Para os tijolos podem-se estudar os tipos de argilas, as técnicas de coleta e preparo além dos tipos de queima e fornos utilizados. Entretanto, o mais promissor será o entendimento das relações sociais dos espaços de tais edificações, o que exigirá um aprofundamento das pesquisas e maior conhecimento com as pessoas que ocuparam aqueles espaços. O diálogo interdisciplinar ocorrido entre a 
Arquitetura e Arqueologia resultou em uma integração que se retroalimenta e gera novos conhecimentos científicos.

Quadro 1: Dados sintetizados da pesquisa.

\begin{tabular}{|c|c|c|c|c|c|c|c|c|c|c|c|c|c|c|}
\hline 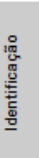 & 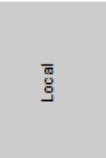 & 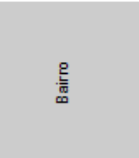 & 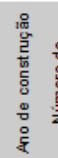 & 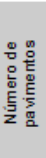 & 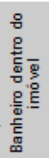 & 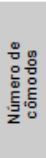 & 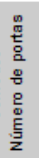 & $\begin{array}{l}\frac{\overline{\frac{m}{5}}}{\Phi} \\
\frac{\mathbb{w}}{2}\end{array}$ & 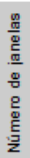 & 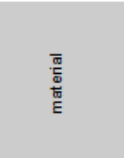 & 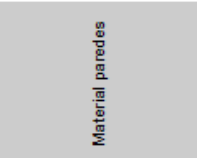 & 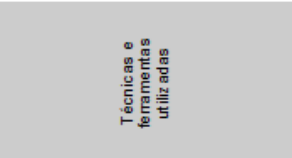 & 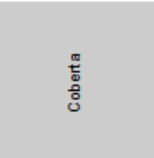 & 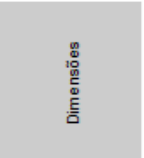 \\
\hline 1 & Fbreste & $\begin{array}{l}\text { Ass entamento } \\
\text { Vtarino }\end{array}$ & 2013 & 1 & Năo & 4 & 2 & Cedro & 2 & $\begin{array}{l}\text { Umbarana de } \\
\text { chero }\end{array}$ & Bero e taipe & $\begin{array}{l}\text { Estacas de madeiras fincadas no s oloe } \\
\text { revestidas embarro }\end{array}$ & Pereiro, slgarcha & $\begin{array}{c}\text { largra } 5 \mathrm{~m}, \\
\text { profundidade } 10 \mathrm{~m}\end{array}$ \\
\hline 2 & Fbresta & $\begin{array}{l}\text { Assentamento } \\
\text { Vtorino }\end{array}$ & 1990 & 1 & Năo & 4 & 2 & Cedro & 0 & - & Berro e taipe & $\begin{array}{l}\text { Estacas de mederias fircades no soloe } \\
\text { reverstidas em berro }\end{array}$ & Pereiro, sgarche & $\begin{array}{l}\text { largura } 5 \mathrm{~m} \text {, } \\
\text { profundidade } 6 \mathrm{~m}\end{array}$ \\
\hline 3 & Flbeste & $\begin{array}{l}\text { Assentamento } \\
\text { Vtarino }\end{array}$ & - & 1 & Năo & 1 & 1 & Cedro & 1 & $\begin{array}{l}\text { Umbarang de } \\
\text { chero }\end{array}$ & Bero e taipe & $\begin{array}{l}\text { Estacas de mederas fircades no soloe } \\
\text { revestidas embarro }\end{array}$ & Pereiro, slgarcha & $\begin{array}{l}\text { largra } 4 \mathrm{~m} \text {, } \\
\text { profundidade } 4 \mathrm{~m}\end{array}$ \\
\hline 4 & Fbresta & Bairo DNR & - & 1 & Nă & 2 & 2 & Cedro & 0 & - & Baro etaipe & $\begin{array}{l}\text { Estacas de maderas fircadas no soloe } \\
\text { reverstidas em berro }\end{array}$ & Pereiro, algarcha & $\begin{array}{l}\text { largra } 4 \mathrm{~m} \text {, } \\
\text { profundidede } 8 \mathrm{~m}\end{array}$ \\
\hline 5 & Fbrest to & Bairo DNR & 2001 & 1 & Nă & 5 & 2 & Cedro & 1 & $\begin{array}{l}\text { Umbarana de } \\
\text { chero }\end{array}$ & Baro etaipa & $\begin{array}{l}\text { Estacas de mederas fircadas no soloe } \\
\text { reverstidas em barro }\end{array}$ & Pereiro, algarcha & $\begin{array}{l}\text { largra } 5 \mathrm{~m} \text {, } \\
\text { profundidade } 8 \mathrm{~m}\end{array}$ \\
\hline 6 & Fbresta & Bairo DNR & 1990 & 1 & Năo & 1 & 2 & - & 1 & - & $\begin{array}{l}\text { Barro, tripa e tijdos } \\
\text { meciposs }\end{array}$ & 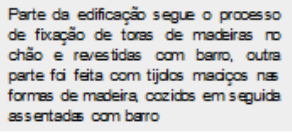 & 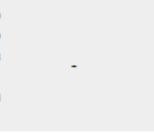 & - \\
\hline 7 & Fbreste & Centro & $17 \pi$ & 2 & Năo & 4 & 4 & $\begin{array}{l}\text { Anvores } \\
\text { nativas }\end{array}$ & 13 & Ánores native & 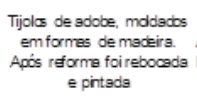 & $\begin{array}{l}\text { Assentamento de tijols de sodbe com } \\
\text { barro }\end{array}$ & - & $300 \mathrm{~m}$ de áres \\
\hline 8 & Fbresta & Nazaré do Fico & 1964 & 1 & Nằ & 6 & 2 & $\begin{array}{l}\text { Untourna } \\
\text { c } \\
\text { ramhản }\end{array}$ & 1 & $\begin{array}{l}\text { Umburana de } \\
\text { cambä́o }\end{array}$ & Barra taips e cal & $\begin{array}{l}\text { Estacas de mediras fircades no soloe } \\
\text { revestidas embarro }\end{array}$ & Avgicoe arosira & $\begin{array}{c}\text { largra } 6 \mathrm{~m} \text {, } \\
\text { profundidade } 8 \mathrm{~m}\end{array}$ \\
\hline 9 & Fbresto & Nazaré do Fico & 2004 & 1 & Sim & 10 & 2 & $\begin{array}{l}\text { Unbursens } \\
\text { de cheiro }\end{array}$ & 4 & $\begin{array}{l}\text { Unburna de } \\
\text { chero }\end{array}$ & Baro e taipa & $\begin{array}{l}\text { Estacas de mederas fircadas no soloe } \\
\text { revestidas em barro }\end{array}$ & Bergúna & $\begin{array}{l}\text { largra } 8 \mathrm{~m}, \\
\text { profundicade } 15 \mathrm{~m}\end{array}$ \\
\hline 10 & Fbresta & Nazaré do Pico & 1997 & 1 & Sim & 6 & 2 & $\begin{array}{l}\text { Unbursas } \\
\text { / pau } \\
\text { daroo }\end{array}$ & 2 & $\begin{array}{l}\text { Umburara / pau } \\
\text { darco }\end{array}$ & Baro e trips & $\begin{array}{l}\text { Estacas farm fincadis so sola } \\
\text { brechas revestidas em barro e cepoí } \\
\text { alis solo }\end{array}$ & $\begin{array}{l}\text { Pereio e soeira - } \\
\text { limas, baraina - } \\
\text { caibros }\end{array}$ & $\begin{array}{l}\text { largra } 5 \mathrm{~m} \text {, } \\
\text { profundidede } 8 \mathrm{~m}\end{array}$ \\
\hline 11 & Fbresta & Ari & 1994 & 1 & Nằ & 6 & 2 & Cedro & 2 & $\begin{array}{l}\text { Umburana de } \\
\text { chero }\end{array}$ & $\begin{array}{l}\text { Berro, taipa e tijdos } \\
\text { macicoss }\end{array}$ & 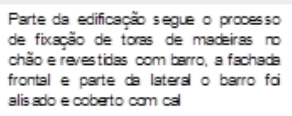 & Pereiroe algarobs & $\begin{array}{c}\text { largara } 8 \mathrm{~m}, \\
\text { profundicade } 11 \mathrm{~m}\end{array}$ \\
\hline 12 & Fbresta & Ari & 1950 & 1 & Sim & 10 & 4 & Cedro & 6 & $\begin{array}{l}\text { umburana de } \\
\text { chero }\end{array}$ & $\begin{array}{l}\text { Tijolos de adobe em } \\
\text { formato de praslekpipedio e } \\
\text { meia lus feitos em forms } \\
\text { de madeira }\end{array}$ & $\begin{array}{l}\text { O barro fai colocado nas famas de } \\
\text { madira, secos pimeiro a sambra } \\
\text { depás } 90 \text { sol, assentados em barro }\end{array}$ & Pereiro earoera & $\begin{array}{l}\text { largra } 9 \mathrm{~m}, \\
\text { profundichde } 18,5 \mathrm{~m}\end{array}$ \\
\hline 13 & Fbresto & Ari & 1999 & 1 & Sim & 6 & 2 & Cedro & 3 & $\begin{array}{l}\text { Umburana de } \\
\text { chero }\end{array}$ & $\begin{array}{l}\text { Barro, tripa e tijdos } \\
\text { mecicoss }\end{array}$ & $\begin{array}{l}\text { Las cas de mackirs fincactas so sola } \\
\text { preenchicas combarno e tildos macicios } \\
\text { feitas em formes de mackira }\end{array}$ & Perciro e aroers & $\begin{array}{l}\text { largra } 8 \mathrm{~m} \text {, } \\
\text { pofurdidack } 8,5 \mathrm{~m}\end{array}$ \\
\hline 14 & Fbresta & Ari & 1910 & 1 & Sim & 5 & 2 & Cedro & 3 & $\begin{array}{l}\text { umburana de } \\
\text { chero }\end{array}$ & $\begin{array}{c}\text { Tijdos de actbee, cimerto } e \\
c a l\end{array}$ & $\begin{array}{l}\text { Formes de macira pasa madulaçäo do } \\
\text { barroe fitras vegetais }\end{array}$ & $\begin{array}{l}\text { Aroera, basaúna e } \\
\text { persio }\end{array}$ & $\begin{array}{c}\text { lagura } 10 \mathrm{~m} \\
\text { profundichde } 12 \mathrm{~m}\end{array}$ \\
\hline 15 & Fbresta & Ari & 1928 & 2 & Nลัo & 2 & 3 & Cedro & 7 & $\begin{array}{l}\text { Umburana de } \\
\text { cherio }\end{array}$ & $\begin{array}{c}\text { Tijols de sobose, rebocace } \\
\text { e pritads }\end{array}$ & $\begin{array}{l}\text { Assentamento de tijols de godde com } \\
\text { barro }\end{array}$ & Bgaúna e aroeira & $300 \mathrm{~m}$ de área \\
\hline 16 & $\begin{array}{l}\text { Carnaubeira } \\
\text { da Penha }\end{array}$ & Centro & - & 1 & Sim & - & 2 & $\begin{array}{l}\text { Madera } \\
\text { nativa }\end{array}$ & 6 & Modeira nativa & 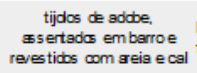 & $\begin{array}{l}\text { Formes de mackira para confecopöes de } \\
\text { tijols }\end{array}$ & - & $\begin{array}{c}\text { Isgura } 10 \mathrm{~m} \\
\text { profundicade } 20 \mathrm{~m}\end{array}$ \\
\hline 17 & $\begin{array}{l}\text { Carnaubeira } \\
\text { da Penha }\end{array}$ & Jaburu & 1996 & 1 & Nä० & 1 & 1 & Cedro & 1 & $\begin{array}{l}\text { Umburana de } \\
\text { chero }\end{array}$ & Taips e baro & $\begin{array}{l}\text { Estacas de mederas fircadas no soloe } \\
\text { reventidas em berro }\end{array}$ & Pereiro e aroera & $\begin{array}{l}\text { largra } 4 \mathrm{~m} \text {, } \\
\text { profundidade } 5 \mathrm{~m}\end{array}$ \\
\hline 18 & $\begin{array}{l}\text { Carnaubeira } \\
\text { da Pennra }\end{array}$ & Jaburu & 1994 & 1 & Näo & 5 & 2 & $\begin{array}{l}\text { Unturnse } \\
\text { de cheiro }\end{array}$ & 0 & - & Baro e tripa & $\begin{array}{l}\text { Estacas de mederas fircadas no soloe } \\
\text { reverstidas em berro }\end{array}$ & $\begin{array}{l}\text { Pereiro-caibro, } \\
\text { berána-linha }\end{array}$ & $\begin{array}{l}\text { largra } 6 \mathrm{~m} \text {, } \\
\text { prdundicade } 10 \mathrm{~m}\end{array}$ \\
\hline 19 & $\begin{array}{l}\text { Carnaubeira } \\
\text { de Penha }\end{array}$ & Jaburu & 1903 & 2 & Năo & 10 & 3 & Cedo & 10 & $\begin{array}{l}\text { Umburana de } t \\
\text { chero }\end{array}$ & $\begin{array}{c}\text { tijdos de sdche, rebocados } \\
\text { combarroe cal }\end{array}$ & Tijoles de sdobe & $\begin{array}{l}\text { Baraúna e aroeira- } \\
\text { linhas, pereiro epau } \\
\text { darco-cabros }\end{array}$ & $\begin{array}{l}\text { Largura } 18,8 \mathrm{~m} \\
\text { profundidade } 12,2 \mathrm{~m}\end{array}$ \\
\hline 20 & $\begin{array}{l}\text { Carnaubeira } \\
\text { da Penta }\end{array}$ & Jaburu & 1979 & 1 & Năo & 8 & 2 & Cedro & 4 & $\begin{array}{l}\text { Umburana de } \\
\text { chero }\end{array}$ & Baro e taipe & $\begin{array}{l}\text { Estaces de madiras fircadas no soloe } \\
\text { reverstidas embarro }\end{array}$ & Bgaúna e periro & $\begin{array}{c}\text { lagura } 11 \mathrm{~m} \\
\text { profundidade } 8 \mathrm{~m}\end{array}$ \\
\hline 21 & $\begin{array}{l}\text { Carnaubeirs } \\
\text { de Penha }\end{array}$ & Jaburu & 1890 & 1 & Năo & 8 & 2 & Cedro & 7 & $\begin{array}{l}\text { Unburne de T } \\
\text { chero }\end{array}$ & $\begin{array}{c}\text { Tijdos de sodbe, revestidos } \\
\text { en baro ecal }\end{array}$ & $\begin{array}{l}\text { Formes de mackira pers confecọöes de } \\
\text { tijols }\end{array}$ & $\begin{array}{l}\text { Bergúba e camaúbe } \\
\text { - linhas, pereioe } \\
\text { groera - caibros }\end{array}$ & $\begin{array}{l}\text { laggura } 14 \mathrm{~m} \\
\text { profundicade } 14 \mathrm{~m}\end{array}$ \\
\hline 22 & $\begin{array}{l}\text { Carnaubeira } \\
\text { da Penta }\end{array}$ & Mæs spè & - & 1 & Năo & 5 & 2 & Ferro & 1 & Ferro & $\begin{array}{l}\text { Restos de tijolos macicos } \\
\text { de outra eáficag̣ies }\end{array}$ & r & $\begin{array}{l}\text { Ripgs de } \\
\text { mameleiro, priro- } \\
\text { caibros }\end{array}$ & $\begin{array}{l}\text { Largura } 3,5 \mathrm{~m} \\
\text { profundidade } 10 \mathrm{~m}\end{array}$ \\
\hline 23 & $\begin{array}{l}\text { Carnaubeira } \\
\text { da Penha }\end{array}$ & MÆs spè & 1980 & 1 & Nล̃o & - & 1 & Cedro & 8 & $\begin{array}{l}\text { umburana de } \\
\text { cherio }\end{array}$ & $\begin{array}{l}\text { tijols de gobobe feitos } \mathrm{em} \\
\text { formes de madeirs }\end{array}$ & $\begin{array}{l}\text { Formes de mackira para confecopoes de } \\
\text { tijols }\end{array}$ & Finho e eucalipto & $\begin{array}{l}\text { Isgura } 20 \mathrm{~m} \\
\text { profundidade } 7 \mathrm{~m}\end{array}$ \\
\hline 24 & $\begin{array}{l}\text { Carnabeira } \\
\text { da Pentra }\end{array}$ & $\begin{array}{l}\text { Serra do Arspuá- } \\
\text { Aldedia Boqueräo }\end{array}$ & 2008 & 1 & Não & 4 & 2 & . & & - & $\begin{array}{l}\text { Tijolas meciços, } \\
\text { assentados em berro }\end{array}$ & Funchẹão em pedra tijdos macị̧s & - & $\begin{array}{l}\text { largrara } 7 \mathrm{~m} \\
\text { profundidade } 7 \mathrm{~m}\end{array}$ \\
\hline 25 & $\begin{array}{l}\text { Carnabeira } \\
\text { de Penha }\end{array}$ & $\begin{array}{l}\text { Sera di Arsoú- } \\
\text { Aldesia Boquerão }\end{array}$ & 2000 & 1 & Năo & 6 & 2 & $\begin{array}{l}\text { Madera } \\
\text { nativa }\end{array}$ & 4 & Madera nativa & Taipe e baro & $\begin{array}{l}\text { Estacas de mederas fircadas no soloe, } \\
\text { revestidas em barro }\end{array}$ & Mamelero e aroeira & $\begin{array}{l}\text { lagurs } 15 \mathrm{~m} \\
\text { profundidade } \mathrm{m}\end{array}$ \\
\hline 26 & $\begin{array}{l}\text { Carnabeira } \\
\text { daPenha }\end{array}$ & $\begin{array}{l}\text { Serra di Arspuá- } \\
\text { Aldsia Boqueräo }\end{array}$ & 1998 & 1 & Năo & 6 & 2 & $\begin{array}{l}\text { Meders } \\
\text { nativa }\end{array}$ & 2 & Madeira nativa $s$ & $\begin{array}{l}\text { Tjijles macicos, } \\
\text { sosentados em baro, cal } \mathrm{e} \\
\text { greia }\end{array}$ & $\begin{array}{l}\text { Formes de madkira para confecọöes de } \\
\text { tijols }\end{array}$ & $\begin{array}{l}\text { Casiba-cabros, } \\
\text { madera ntiva pars } \\
\text { as linhas }\end{array}$ & $\begin{array}{l}\text { Largra } 12,9 \mathrm{~m} \\
\text { pofurdidace } 6,8 \mathrm{~m}\end{array}$ \\
\hline 27 & $\begin{array}{l}\text { Carnaubeirs } \\
\text { da Penhra }\end{array}$ & $\begin{array}{l}\text { Sera do Arspúa - } \\
\text { Ableis Pitonbeira }\end{array}$ & 2008 & 1 & Năo & 7 & 2 & $\begin{array}{l}\text { Meders } \\
\text { nativa }\end{array}$ & 4 & Medera nativa & Taipa e baro & $\begin{array}{l}\text { Estacas de mederas fircadas no soloe } \\
\text { revestidas em berro }\end{array}$ & Argicoe sroeira & $\begin{array}{l}\text { largra } 8 \mathrm{~m}, \\
\text { profundidade } 13 \mathrm{~m}\end{array}$ \\
\hline 28 & $\begin{array}{l}\text { Carnaubeira } \\
\text { da Penta }\end{array}$ & $\begin{array}{l}\text { Sera di Arspú- } \\
\text { Ableia Pitombeira }\end{array}$ & 2013 & 1 & Năo & 4 & 2 & $\begin{array}{l}\text { Medera } \\
\text { nativa }\end{array}$ & 3 & Modeira nativa & Taipa e baro & $\begin{array}{l}\text { Estacas de medeiras fircadas no soloe } \\
\text { revestidas em barro }\end{array}$ & Avoeira & $\begin{array}{l}\text { largra } 6 \mathrm{~m}, \\
\text { pofurdidack } 5,5 \mathrm{~m}\end{array}$ \\
\hline
\end{tabular}




\section{Referência}

CARRÉRA, M. SURYA, L.. Arqueologia da arquitetura: contribuição nos projetos de restauro e na preservação. Revista Architecton, Recife. 2012

CARVALHO. A. P. B. de. História da evolução urbana da cidade de Floresta- PE. (Trabalho de conclusão do curso em História do Nordeste). Centro de Ensino Superior do Vale do São Francisco, Belém do São Francisco. 2003.

COSTA, L. Arquitetura. Ed. José Olympio, São Paulo. 2002.

FERREIRA, A. B. de H, Mini Aurélio, minidicionário do Séc. XXI escolar. Rio de Janeiro: Ed. Nova Fronteira, 2001.

ICOMOS - CONSELHO INTERNACIONAL DE MONUMENTOS E SÍTIOS. 1999. Carta sobre patrimônio vernacular edificado, México. Disponível em: <http://www.icomos.org.br/ cartas/Carta\%20sobre\%20o\%20patrim\%C3\%B4nio20vernacular\%20edificado\%20-\%201999.pdf>.Acesso em: 10 de março de 2014.

LIMA, R. R.. Arquitetura vernacular e habitação de interesse social. 2010. Disponível em: <http:// www.anparq.org.br/dvd-enanparq/simposios/51/51-651-1-SP.pdf> acesso em: 13 de abril de 2014.

MAÑANA BORRAZÁS, P.; BLANCO ROTEA, R.; e AYÁN VILA, X. 2002. Arqueotectura I: Bases teóricometodológicas para una Arqueología de la Arquitectura. TAPA Traballos de Arqueoloxía e Patrimonio, 25, Santiago de Compostela: Laboratorio de Patrimonio, Paleoambiente e Paisaxe, pp. 11-99.

MANNONI, T.; BOATO, A., "Archeologia e storia del cantiere di costruzione", in Arqueología de la Arquitectura, 1, Vitoria-Gasteiz: Diputació Foral de Álava, Universidad del País Vasco e CSIC, pp. 39-53, 2002.

MAIA, G. A colonização do Nordeste brasileiro e os sertões. 2014. Disponível em: <http://blogdogeohistoria.blogspot.com.br/2009/06/colonizacao-do-nordeste-brasileiro-eos.html> acesso em: 16 de abril de 2014 .

MENDES, C.; VERISSíMO, C.; BITTAR, W. Arquitetura no Brasil. De Cabral a Dom João VI. Ed. Imperial Novo Milênio, Rio de Janeiro. 2011.

SILVA, E. Matéria, Ideia e Forma. Uma definição de arquitetura. Ed. UFRGS, Rio Grande do Sul. SOUZA, Alves de apud TEIXEIRA, Claudia Mudado. 2008. Considerações sobre arquitetura vernácula. Minas Gerais: Caderno de arquitetura e urbanismo, Belo Horizonte. 1994.

TEIXEIRA, C. M. Considerações sobre arquitetura vernacular. Ed. PUC MINAS, Minas Gerais. 2008. 